\title{
Editorial
}

\section{GTH 2021: ACROSS BORDERS}

Lorenzo Alberio ${ }^{1}$

\footnotetext{
${ }^{1}$ Service et Laboratoire central d'hématologie, Centre Hospitalier Universitaire Vaudois (CHUV), Université de Lausanne (UNIL), Switzerland
}

Hämostaseologie 2021;41:5-8.

“Bienvenue!”, “Benvenuti!”, “Willkommen!”, “Welcome!” to the GTH 2021 congress, simply online ... worth experiencing. During the Opening Ceremony, which will take place on Monday, February 22, you will enjoy, among other inspiring presentations (check on www.gth2021.org), the Alexander Schmidt Lecture held by the Awardee Markus Bender. The corresponding manuscript by Bender and Palankar, ${ }^{1}$ masterfully summarizing recent findings on the contribution of the actin cytoskeleton and lamellipodia structures to platelet function, opens this year's congress issue of Hämostaseologie - Progress in Haemostasis.

Haemostasis is just fascinating! In my experience, one of the several reasons is its interdisciplinary character, which we realize daily, discussing clinical cases with colleagues from other medical specialties: in emergency rooms and operating theatres, on paediatric wards, in the lab and in clinics as diverse as hepatology, obstetrics, vascular medicine, or haemato-oncology. With the motto ACROSS BORDERS, the $2021 \mathrm{GTH}$ congress will focus on interdisciplinary aspects of haemostasis, opening the doors to colleagues from other medical fields, and opening the minds towards different points of view and ways of thinking about haemostasis (see the topics of plenaries on www.gth2021.org). Some of the invited speakers have enthusiastically accepted the opportunity to submit a conceptual manuscript summarizing key points of their lectures. Here you can read the first series.

The first section is dedicated to the fields of Neurology and Cardiovascular Medicine. Vivien (Plenary, February 23, 2021) allows a brief glimpse into "across border" research activities of his group and stimulates our curiosity on several topics. ${ }^{2}$ For example, how to overcome the limits of animal models for studying human stroke. The intriguing fate of $\mathrm{N}$ acetylcysteine, a mucolytic drug employed as an antidote for paracetamol overdose, which is now becoming a candidate for treating acute ischaemic stroke, because of its ability to depolymerize von Willebrand factor. ${ }^{3}$ The effects of tissue plasminogen activator in the brain, which affect neuronal survival and migration, synaptic plasticity, and even memory and anxiety. Of note, this latter surprising connection will be the topic of the lecture by Robert Medcalf, during the Plenary "Think Across Borders" on Friday, February 26 ("Don't miss it!"). Aguiar de Sousa (state of the art, SoA, "Neurology", February 24, 2021) updates our knowledge on cerebral venous thrombosis. ${ }^{4}$ She addresses the quite variable clinical presentation, the lack of strong evidence in favour of endovascular treatment approaches, the available data on the use of direct oral anticoagulants (DOACs) compared to vitamin K antagonists (VKAs), and criteria for defining the duration of anticoagulant treatment. De Marchis (SoA "Cardiology Neurology", February 23, 2021) summarizes clinical key aspects of the use of DOAC after ischaemic stroke, ${ }^{5}$ highlighting the observation that the rate of intracranial haemorrhage is halved and mortality is significantly decreased in patients on extended anticoagulation with DOAC compared to VKA. He thoroughly discusses the impact of past medical history and current clinical setting on the choice of the drug (i.e. aspirin, DOAC, VKA), its dosage and timing of start, and the risk of subsequent haemorrhagic complications. BeyerWestendorf (SoA "Cardiology - Neurology", February 23, 2021) summarizes published evidence from phase 3 studies on DOAC in atrial arrhythmias and addresses clinically relevant, frequently asked questions, such as dose adaptation in renal impairment, drug interactions, food intake, obesity, and antidotes. ${ }^{6}$

The second section deals with Haematology and Oncology. Blondon (SoA, "Venous Thromboembolism", February 26,2021$)$ discusses how to investigate patients with venous thromboembolism (VTE) in order identify those (about $5 \%$ ) with an occult cancer. ${ }^{7}$ A limited diagnostic work-up identifies the majority of occult cancers, thus reducing the risk of false-positive signals generated by performing a computed tomography- or positron emission tomography-scan in all patients. While currently available
Address for correspondence

Prof. Dr. med. Lorenzo Alberio, University Hospital of Lausanne, Division of Haematology and Central Haematology Laboratory, Rue du Bugnon 46, CH-1011 Lausanne, Switzerland (e-mail: lorenzo.alberio@chuv.ch). (c) 2021. Thieme. All rights reserved. Georg Thieme Verlag KG, Rüdigerstraße 14,

70469 Stuttgart, Germany

Received

December 21, 2020

Accepted

December 21, 2020
DOI https://doi.org/ 10.1055/a-1339-8683. ISSN 0720-9355. 
prediction models do not identify patients at increased risk, some clinical situations (such as upper extremity vein thrombosis, bilateral and/or descending deep vein thrombosis, splanchnic vein thrombosis, ${ }^{8}$ cerebral vein thrombosis, ${ }^{4}$ and recurrent VTE despite anticoagulation) appear to be associated with an increased likelihood to detect an occult cancer. Falanga et al (SoA "Haemato-Oncology B", February 25,2021 ) thoroughly address in a didactically wellwritten and illustrated manuscript the pathogenesis, prevention, and management (including published experience with DOAC) of thromboembolic events in BCR/ABL-negative myeloproliferative neoplasms (MPN). ${ }^{8}$ Some noteworthy points are (1) the high number of patients experiencing thromboembolic events before or at the time of diagnosis of MPN (about 20\%); (2) the rationale $e^{9,10}$ and proposed indications for administering aspirin twice daily; and (3) the clinical impact of reducing the allelic burden of the driver mutations, which can be achieved with interferon, JAKinhibitors, and even busulfan. Ranta and Scala (SoA "Coagulation in Critical Care", February 24, 2021) conclude the haematology section with an up-to-date review on current pathophysiologic concepts and practical strategies for anticoagulating patients with heparin-induced thrombocytopenia requiring cardiac surgery. ${ }^{11}$

The third section deals with new concepts in Haemostasis. Lillicrap and Rawley (SoA "News on Haemostatic Factors", February 24, 2021) in a nicely illustrated contribution $^{12}$ recapitulate the structure and known intracellular functions of the von Willebrand factor propeptide (VWFpp), i.e. facilitation of intermolecular disulphide linkages generating high-molecular-weight VWF multimers and development of the endothelial storage organelles, the WeibelPalade bodies. In addition, the authors explore possible extracellular functions of VWFpp (in particular conflicting results on its role in platelet aggregation and the rational for a role in angiogenesis) and discuss diagnostic utility as a biomarker for endothelial cell activation or VWF clearance. The issue is rounded up by the very informative contribution of Longstaff (SoA “Laboratory Methods", February 26, 2021), which covers technical aspects, interpretation, and diagnostic utility of laboratory methods for assessing fibrinolysis. His presentation also offers some insights into the role of fibrinolysis biomarkers in COVID-19 patients. ${ }^{13}$

I thank the Editor-in-Chief of Hämostaseologie - Progress in Haemostasis, Prof. Rüdiger Scharf, for the opportunity to shape this congress issue. ${ }^{14}$ I also thank Dr. Elinor Switzer and the reviewers, who, working in the shadow, greatly helped improving the quality of the submitted papers. On average, I asked five colleagues (range: $4-8$ ) in order to obtain two reviewers per manuscript. The median time required for the first review was 24 days (12-78) and for the second 5 days. ${ }^{1-10}$ Overall, the median time between submission and final acceptance was 40 days (20-118). This is a major achievement, considering that the reviewers' work is usually performed after the daily work, evenings, and on weekends, far away from the limelight.

I thank the authors, who performed a masterful job and who delivered - despite the ongoing second COVID-19 pandemic wave - their manuscript timely. Ten manuscripts appear in this issue and a further 11 are planned for a second congress issue of Hämostaseologie - Progress in Haemostasis.

I thank the readers, who dedicating their time to these articles will honour the authors' efforts ... and will gain new precious insights into some aspects of "Interdisciplinary Haemostasis".

Enjoy this fine collection of review articles and listen to the authors' presentations available on demand at www. gth2021.org.

Conflict of Interest

The author declares that he has no conflict of interest.

\section{References}

1 Bender M, Palankar R. Platelet shape changes during thrombus formation: the role of actin-based protrusions. Hamostaseologie 2021;41(01):14-21

2 Vivien D. New opportunities for diagnosis and prognosis of stroke: the benefit of across border approaches. Hamostaseologie 2021;41(01):22-24

3 Chen J, Reheman A, Gushiken FC, et al. N-acetylcysteine reduces the size and activity of von Willebrand factor in human plasma and mice. J Clin Invest 2011;121(02):593-603

4 Aguiar de Sousa D. Cerebral venous thrombosis - What's new? Hamostaseologie 2021;41(01):25-30

5 De Marchis GM. DOAC after ischemic stroke: Which patient? Which drug? And how early?. Hamostaseologie 2021;41(01): $31-34$

6 Beyer-Westendorf J. DOAC in atrial arrhythmias: current state of the art. Hamostaseologie 2021;41(01):35-41

7 Blondon M. Screening for cancer in patients with acute venous thromboembolic disease. Hamostaseologie 2021;41(01):42-47

8 Falanga A, Marchetti M, Schieppati F. Revention and management of thrombosis in BCR/ABL-negative myeloproliferative neoplasms. Hamostaseologie 2021;41(01):48-56

9 Clarke RJ, Mayo G, Price P, FitzGerald GA. Suppression of thromboxane A2 but not of systemic prostacyclin by controlled-release aspirin. N Engl J Med 1991;325(16):1137-1141

10 Pascale S, Petrucci G, Dragani A, et al. Aspirin-insensitive thromboxane biosynthesis in essential thrombocythemia is explained by accelerated renewal of the drug target. Blood 2012;119(15): 3595-3603

11 Ranta L, Scala E. The perioperative management of heparininduced thrombocytopenia. Hamostaseologie 2021;41(01): 57-60

12 Lillicrap D, Rawley O. Functional roles of the von Willebrand factor propeptide. Hamostaseologie 2021;41(01):61-66

13 Longstaff C. Measuring fibrinolysis. Hamostaseologie 2021;41 (01):67-73

14 Scharf RE. How the COVID-19 pandemic impacts lives of life scientists. Hamostaseologie 2021;41(01):9-12 